Abstract 81 Table 1 Main demographic data, clinical and laboratory features in the studied groups

\begin{tabular}{|c|c|c|c|c|}
\hline & SLE no aPL, n (\%) & SLE APS, n (\%) & SLE aPL, n (\%) & $p$ \\
\hline Female sex & $2075(90.9 \%)$ & $455(88.3 \%)$ & $757(90.1 \%)$ & 0.178 \\
\hline Age, mean $\pm S D(y r)$ & $47.0 \pm 15.1$ & $48.5 \pm 14.4$ & $45.3 \pm 14.3$ & $<0.001$ \\
\hline Disease duration, mean $\pm \mathrm{SD}(\mathrm{mo})$ & $141.5 \pm 100.7$ & $156.8 \pm 109.8$ & $136.4 \pm 94.0$ & 0.001 \\
\hline Tobacco use: & $335(16.3)$ & $91(18.6)$ & $125(16.6)$ & 0.743 \\
\hline - Current & $494(24.1)$ & $119(24.3)$ & $189(25.2)$ & \\
\hline \multicolumn{5}{|l|}{ - Former } \\
\hline High blood pressure & $647(28.6)$ & $211(40.1)$ & $203(24.4)$ & $<0.001$ \\
\hline Dyslipidemia & $664(30.3)$ & $216(41.9)$ & $221(27.3)$ & $<0.001$ \\
\hline \multicolumn{5}{|l|}{ Diabetes: } \\
\hline Without organ damage & $97(4.3)$ & $29(5.6)$ & $25(3)$ & \\
\hline With organ damage & $17(0.8)$ & $8(1.5)$ & $3(0.4)$ & 0.022 \\
\hline Cutaneous manifestations & $1700(74.4)$ & $358(67.4)$ & $611(72.7)$ & 0.005 \\
\hline Joint symptoms & $636(27.8)$ & $164(30.9)$ & $204(24.3)$ & 0.022 \\
\hline Respiratory manifestations & $241(10.5)$ & $125(23.5)$ & $70(8.3)$ & $<0.001$ \\
\hline Cardiac manifestations & $379(16.6)$ & $159(29.9)$ & $125(14.9)$ & $<0.001$ \\
\hline Renal manifestations & $862(37.7)$ & $249(46.9)$ & $298(35.4)$ & $<0.001$ \\
\hline Neuropsychiatric manifestations & $655(28.7)$ & $235(44.3)$ & $238(28.3)$ & $<0.001$ \\
\hline Ophthalmological manifestations & $315(13.8)$ & $111(20.9)$ & $103(12.2)$ & $<0.001$ \\
\hline Positive anti DNA antibodies & $1049(46.9)$ & $258(50)$ & $367(45.1)$ & $<0.001$ \\
\hline Hypocomplementemia & $1716(76.7)$ & $424(82.8)$ & $645(77.9)$ & 0.011 \\
\hline
\end{tabular}

investigate the differences between SLE patients according to the presence of aPL and/or clinical antiphospholipid syndrome (APS).

Methods Patients from the RELESSER-T registry were included. RELESSER-T is a multicenter, hospital-based registry, with retrospective cross-sectional collection of data from a large representative sample of adult non-selected patients with SLE attending Spanish rheumatology services from the public national health system.

Results We included 3651 SLE patients and 1368 were positive for aPL $(44.9 \%$ of patients were positive for anticardiolipin antibodies, $27.3 \%$ showed positivity for anti b2glycoprotein I and 24\% for lupus anticoagulant). Overall 2283 patients were classified as SLE no aPL, 528 as SLEAPS and 840 as SLE-aPL. Demographic data, clinical and laboratory features in the different groups are showed in table 1. Regarding cardiovascular risk factors, SLE-APS patients had higher rates of hypertension, dyslipidemia and diabetes than SLE-aPL and SLE no aPL patients $(p<0.001$, $\mathrm{p}<0.001$ and $\mathrm{p}=0,022$, respectively). SLE-APS patients showed a lower prevalence of photosensitivity and higher frequencies of serositis, proteinuria ( $>0.5$ grs), urinary cell casts, seizures and psychosis (p0.001). Overall, SLE-APS patients showed a lower rate of cutaneous manifestations and higher rates of neuropsychiatric, cardiac, pulmonary, renal, joint and ophthalmological manifestations (table 1). In accordance with a more severe clinical profile, higher frequency of anti-DNA antibodies and hypocomplementemia were observed in the SLE-APS group $(p<0.001)$. In addition to a higher disease activity (SLEDAI), SLE APS patients presented more damage accrual with higher values in SLICC $(1.9 \pm 2.2$ in SLE APS, $0.9 \pm 1.4$ in SLE aPL and $1.1 \pm 1.6, \mathrm{p}<0.001)$ and Katz indexes $(3 \pm 1.8$ in SLE APS, $2.7 \pm 1.7$ in SLE aPL and $2.6 \pm 1.6$ in SLE no aPL, $\mathrm{p}<0.001)$.
Conclusions SLE-APS patients show a more severe clinical profile with higher frequency of major organ involvement and more damage accrual than SLE-aPL and SLE no APL.

Funding Source(s): None

\section{DECREASED EXPRESSION OF ANKRD44 ASSOCIATES WITH THE OVERACTIVATION OF TYPE I IFN SIGNALING PATHWAY IN SLE}

${ }^{1}$ Jian yang Ma*, ${ }^{2}$ Xiao Han, ${ }^{2} \mathrm{Bo}$ Qu, ${ }^{2} \mathrm{Nan}$ Shen. ${ }^{1}$ Shanghai Institute of Rheumatology, Department of Rheumatology, Renji Hospital, Shanghai JiaoTong University School of Medicine; ${ }^{2}$ Department of Rheumatology, Renji Hospital, Shanghai Jiao Tong University School of Medicine

\subsection{6/lupus-2019-Ism.82}

Background Lupus is a complex chronic systemic autoimmune disease. Dysregulation of interferon-alpha (IFN-) response has been associated with the pathogenesis of lupus. Genetic variants constitute the risk factors for the development of lupus, with many SNPs identified to pose the risk of lupus. However, the functions of the host genes of these SNPs are not fully understood. Recent studies show SNP rs4850410 is associated with serum IFN- levels in European-Americans and Afican-Americans. Rs4850410 is located in the intronic region of ANKRD44 which encodes a subunit of ankyin repeat domain of protein phosphatase 6 (PP6) that is involved in an array of important cellular processes, such as the regulation of metabolism, transcription, and apoptosis. However, if ANKRD44 regulates IFN responses is unknown. In this study, we aimed to investigate the function of ANKRD44 in controlling IFN response, and its association with the pathogenesis of lupus. 
Methods PBMCs were collected from 46 SLE patients and 48 healthy controls. The mRNA expression of ANKRD44 and IFN-inducible genes was detected by real time PCR. The mRNA expression of ANKRD44 was measured at different time points in Raw264.7 cells during IFN stimulation. ANKRD44 was knocked down by using siRNA. The activation of IFN signaling pathway were examined by western blotting at different time points in Raw264.7 cells.

Results The mRNA expression levels of ANKRD44 were decreased in PBMCs from SLE patients compared to healthy controls. The expression of ANKRD44 was downregulated when stimulating by poly(I:C) or IFN in Raw264.7 cells. Knockdown of ANKRD44 up-regulated the expression of IFN-inducible genes (such as IFIT3 and CCL2). Consistently, knockdown of ANKRD44 promoted the phosphorylation of STAT1, STAT2, JAK1 and TYK2 stimulated by IFN in Raw264.7 cells.

Conclusions Our study indicates that ANKRD44 functions as a negative regulator in type I IFN signaling pathway. Decreased expression of ANKRD44 constitutes one of the mechanisms for dysregulated IFN response in SLE, which may play important roles in the pathogenesis of Lupus.

Funding Source(s): This work was supported by the National Basic Research Program of China (973 program) grant 2014CB541902 and the National Natural Science Foundation of China (No.81401331).

\section{CLASSIFICATION OF SYSTEMIC LUPUS ERYTHEMATOSUS PATIENTS: THE 2018 EULAR/ACR CRITERIA VS THE 1982/1997 ACR CRITERIA. A COMPARATIVE STUDY IN TWO MULTICENTER MULTIETHNIC COHORTS}

${ }^{1}$ Manuel F Ugarte-Gil ${ }^{*},{ }^{2}$ Guillermo J Pons-Estel, ${ }^{3}$ Russell Griffin, ${ }^{4}$ Guillermina B Harvey, ${ }^{4}$ Daniel Wojdyla, ${ }^{5}$ Luis M Vila, ${ }^{6}$ Loreto Massardo, ${ }^{7}$ Eloisa Bonfa, ${ }^{8}$ Mario Cardiel, ${ }^{9}$ Verónica Saurit, ${ }^{10}$ Enrique Soriano, ${ }^{11}$ Bernardo Pons-Estel, ${ }^{12}$ Graciela S Alarcón. ${ }^{1}$ Universidad Cientifica del Sur; ${ }^{2}$ Grupo Oroño - Centro Regional de Enfermedades Autoinmunes y Reumáticas (GO-CREAR); ${ }^{3}$ Department of Epidemiology, UAB; ${ }^{4}$ Facultad de Ciencias Económicas y Estadística, Universidad Nacional de Rosario, Rosario, Argentina; ${ }^{5}$ Division of Rheumatology. University of Puerto Rico; ${ }^{6}$ Facultad de Medicina y Ciencia. Universidad San Sebastián; ${ }^{7}$ Rheumatology Division, Faculdade de Medicina, Hospital das Clinicas HCFMUSP, Universidade de São Paulo; ${ }^{8}$ Centro de Investigación Clínica de Morelia; ${ }^{9}$ Servicio de Reumatología, Hospital Privado Universitario de Córdoba; ${ }^{10}$ Sección de Reumatología, Servicio de Clínica Médica, Instituto Universitario, Hospital Italiano de Buenos Aires; ${ }^{11}$ Centro Regional del Enfermedades Autoinmunes y Reumáticas (GO-CREAR); ${ }^{12}$ School of Medicine. The University of Alabama at Birmingham

\subsection{6/lupus-2019-Ism.83}

Background The 2018 EULAR/ACR criteria for the classification of patients with systemic lupus erythematosus (SLE) has been a work in progress over the last five years. They have been presented and proposed over the last couple of years being their goal to improve the sensitivity and specificity of the previously published SLE criteria. The aim was to determine the sensitivity of the 2018 EULAR/ACR criteria using two well-defined lupus cohorts.

Abstract 83 Table 1 Comparison of baseline demographic and clinical characteristics by whether the patients met 2018 EULAR/ACR -based diagnosis at the same time, earlier, or later than diagnosis based on 1982/1997 ACR criteria

\begin{tabular}{|c|c|c|c|c|}
\hline & $\begin{array}{l}\text { EULAR/ACR criteria met at the } \\
\text { same time as } 1982 / 1997 \text { ACR criteria }\end{array}$ & $\begin{array}{l}\text { EULAR/ACR criteria met earlier } \\
\text { than the } 1982 / 1997 \text { ACR criteria }\end{array}$ & $\begin{array}{l}\text { EULAR/ACR criteria met later } \\
\text { than the } 1982 / 1997 \text { ACR criteria, }\end{array}$ & \\
\hline & $n=344$ & $\mathrm{n}=41$ & $\mathrm{n}=173$ & $p$-value* \\
\hline \multicolumn{5}{|l|}{ US cohort } \\
\hline \multicolumn{5}{|l|}{ DEMOGRAPHIC } \\
\hline \multicolumn{5}{|l|}{ Race or ethnicity, $n(\%)$} \\
\hline Hispanic (Texan) & $82(23.8)$ & $11(26.8)$ & $21(12.1)$ & $<0.0001$ \\
\hline African-American & $159(46.2)$ & $18(43.9)$ & $46(26.6)$ & \\
\hline Caucasian & $73(21.2)$ & $5(12.2)$ & $65(37.6)$ & \\
\hline Hispanic (Puerto Rican) & $30(8.7)$ & $7(17.1)$ & $41(23.7)$ & \\
\hline \multicolumn{5}{|l|}{ Gender, $\mathrm{n}(\%)$} \\
\hline Female & $307(89.2)$ & $33(80.5)$ & $160(92.5)$ & 0.0725 \\
\hline Male & $37(10.7)$ & $8(19.5)$ & $13(7.5)$ & \\
\hline Age at enrollment, mean (SD) & $34.8(12.4)$ & $34.4(13.1)$ & $37.5(12.6)$ & 0.0604 \\
\hline \multicolumn{5}{|l|}{ CLINICAL } \\
\hline SLAM score at enrollment, mean (SD) & $10.0(6.3)$ & $8.9(5.7)$ & $8.3(4.9)$ & 0.0093 \\
\hline Latin American cohort & $\mathrm{n}=556$ & $\mathrm{n}=71$ & $n=329$ & \\
\hline \multicolumn{5}{|l|}{ DEMOGRAPHIC } \\
\hline \multicolumn{5}{|l|}{ Race or ethnicity, $\mathrm{n}(\%)$} \\
\hline Mestizo & $190(34.2)$ & $43(61.4)$ & $135(41.2)$ & 0.0003 \\
\hline African-Latin-American & $68(12.2)$ & $6(8.6)$ & $29(8.8)$ & \\
\hline Caucasian & $289(52.0)$ & $21(30.0)$ & $154(47.0)$ & \\
\hline Other & $9(1.6)$ & $0(0.0)$ & $10(3.1)$ & \\
\hline \multicolumn{5}{|l|}{ Gender, n (\%) } \\
\hline Female & $497(89.4)$ & $62(87.3)$ & $301(91.5)$ & 0.4500 \\
\hline Male & $59(10.6)$ & $9(12.7)$ & $28(8.5)$ & \\
\hline Age at enrollment, mean (SD) & $29.8(12.8)$ & $30.4(11.6)$ & $29.5(11.7)$ & 0.8580 \\
\hline \multicolumn{5}{|l|}{ CLINICAL } \\
\hline SLEDAI score at enrollment, mean (SD) & $10.9(7.9)$ & $9.3(7.7)$ & $10.7(8.2)$ & 0.3500 \\
\hline
\end{tabular}

* Estimated from a Pearson's Chi-square test and analysis of variance for categorical and continuous variables, respectively 